\title{
Mycotic aneurysm presenting as subdural empyema: illustrative case
}

\author{
Joshua T. M. Lucas, BS, ${ }^{1}$ Shahed Elhamdani, $M D,{ }^{2}$ Seung W. Jeong, $M D,{ }^{2}$ and Alexander $Y u, \mathrm{MD}^{2}$ \\ ${ }^{1}$ Drexel University College of Medicine, Philadelphia, Pennsylvania; and ${ }^{2}$ Department of Neurosurgery, Allegheny General Hospital, Pittsburgh, Pennsylvania
}

BACKGROUND Mycotic aneurysms (MAs) are rare intracranial pathologies. They are associated with spontaneous rupture, which is often the first presenting sign. Subarachnoid hemorrhage and intraparenchymal hemorrhage are the most common sequelae of ruptured MAs, with subdural hematoma being an atypical presentation. The presentation of an MA as a subdural empyema has not yet been reported in the literature.

OBSERVATIONS The authors discussed a 68-year-old man who presented with subdural empyema and received surgery for evacuation. He was found to have a ruptured mycotic aneurysm intraoperatively.

LESSONS This case demonstrated a rare and atypical presentation of an MA.

https://thejns.org/doi/abs/10.3171/CASE21507

KEYWORDS mycotic aneurysm; subdural empyema; subdural hematoma

The term "mycotic aneurysm" (MA) is a misnomer in medicine. Although the term "mycotic" often refers to fungal disease, MA refers to aneurysms that are formed as a result of inflammatory damage to an arterial wall. ${ }^{1}$ MAs account for $<5 \%$ of intracranial aneurysms, with $65 \%$ of them being associated with infective endocarditis. ${ }^{2}$

Intracranial MAs may present unruptured as otherwise unexplained neurological deficits in the setting of infective endocarditis. It has been reported that $65 \%$ of patients with MAs present with bacterial infective endocarditis, with other common sources of infection including intravenous drug use $(6.3 \%)$, bacterial meningitis $(5.2 \%)$, poor dental hygiene $(4.2 \%)$, and cavernous sinus thrombosis $(2.8 \%) .^{3}$ In these settings, characteristic radiological findings in the cerebrovascular system may lead to the diagnosis of an MA. More typically, however, MAs remain clinically silent until spontaneous rupture. Once ruptured, they primarily present as either intracerebral hemorrhage $(\mathrm{ICH})$ or subarachnoid hemorrhage (SAH). ${ }^{4,5}$ Rarely do MAs present as subdural hematoma, with only 13 cases reported in the literature (Table 1). The presentation of an MA as subdural empyema, however, has not been reported in the literature.

\section{Illustrative Case}

\section{Presentation and Preoperative Course}

A 68-year-old man with a history of alcohol abuse, cirrhosis, and morbid obesity presented to his primary care physician with 2 weeks of worsening headaches, fatigue, fever, chills, back pain, posterior neck stiffness, and neck pain. The patient had multiple tooth extractions several weeks earlier secondary to dental caries that he had neglected because of medical costs. His primary care physician sent blood cultures that tested positive for Streptococcus sanguinis. The patient subsequently presented to the emergency department and was admitted to the medicine service for sepsis and presumed meningitis. Computed tomography (CT) of his head on admission did not demonstrate any intracranial pathology. Lumbar puncture performed by the primary service indicated 18 red blood cells, 114 white blood cells, 52 milligrams glucose per deciliter, and 85 milligrams protein per deciliter. Gram stain and culture results were negative. The patient received penicillin per infectious disease recommendations and was monitored in the hospital. During his evaluation, he was also found to have an aortic vegetation with aortic insufficiency.

Despite the initial CT scan of the head demonstrating negative results, the patient's headache continued to worsen while he remained otherwise neurologically intact. A CT scan repeated on hospital day 6 showed left-sided extraaxial fluid collection with 6 $\mathrm{mm}$ of midline shift toward the right. Brain magnetic resonance imaging (MRI) showed the extraaxial collection with diffusion restriction and correlating apparent diffusion coefficient (Fig. 1). There was also an area within the right insular cortex suggestive of stroke.

ABBREVIATIONS CT = computed tomography; ICH = intracerebral hemorrhage; $M A=$ mycotic aneurysm; MRI = magnetic resonance imaging; SAH = subarachnoid hemorrhage . INCLUDE WHEN CITING Published January 24, 2022; DOI: 10.3171/CASE21507.

SUBMITTED September 21, 2021. ACCEPTED October 1, 2021.

(c) 2022 The authors, CC BY-NC-ND 4.0 (http://creativecommons.org/licenses/by-nc-nd/4.0/). 
TABLE 1. Subdural hematoma in the setting of ruptured intracranial MAs

\begin{tabular}{|c|c|c|c|c|c|c|c|c|c|}
\hline Case No. & Authors \& Year & $\begin{array}{l}\text { Age } \\
\text { (yrs) }\end{array}$ & Sex & $\begin{array}{c}\text { Infective } \\
\text { Endocarditis }\end{array}$ & $\begin{array}{l}\text { Involved } \\
\text { Cardiac } \\
\text { Valve }\end{array}$ & $\begin{array}{l}\text { Associated } \\
\text { SAH }\end{array}$ & $\begin{array}{l}\text { Associated } \\
\text { ICH }\end{array}$ & Treatment & Outcome \\
\hline 2 & $\begin{array}{l}\text { Bandoh \& } \\
\text { Sugimura, } \\
1987^{7}\end{array}$ & 26 & $F$ & Yes & Mitral & No & Yes & $\begin{array}{l}\text { Craniotomy, removal of } \\
\text { SDH \& ICH, coagulation } \\
\& \text { cutting of vessel just } \\
\text { distal to aneurysm }\end{array}$ & $\begin{array}{l}\text { Death from } \\
\text { cardiac failure } 5 \\
\text { days later }\end{array}$ \\
\hline 3 & $\begin{array}{c}\text { Barami \& Ko, } \\
1994^{8}\end{array}$ & 36 & $M$ & $\begin{array}{c}\text { Not } \\
\text { reported }\end{array}$ & $\begin{array}{l}\text { Mitral \& } \\
\text { aortic }\end{array}$ & No & Yes & $\begin{array}{l}\text { Antibiotics, no surgical } \\
\text { intervention }\end{array}$ & Vegetative state \\
\hline 4 & $\begin{array}{l}\text { Boukobza } \\
\text { et al., } 2019^{2}\end{array}$ & 54 & $M$ & Yes & Aortic & No & No & $\begin{array}{c}\text { Endovascular glue } \\
\text { embolization }\end{array}$ & Full recovery \\
\hline 7 & King, $1960^{10}$ & 23 & $\mathrm{~F}$ & Yes & Mitral & No & No & $\begin{array}{l}\text { Craniotomy, removal of } \\
\text { aneurysm \& hematoma }\end{array}$ & Good recovery \\
\hline 8 & $\begin{array}{l}\text { Lee et al., } \\
2013^{4}\end{array}$ & 72 & $M$ & No & $\begin{array}{c}\text { Not } \\
\text { reported }\end{array}$ & No & No & $\begin{array}{c}\text { Antibiotics, no surgical } \\
\text { intervention }\end{array}$ & Full recovery \\
\hline 9 & $\begin{array}{l}\text { Matsuda et al., } \\
2002^{11}\end{array}$ & 22 & $F$ & Yes & Mitral & Yes & No & $\begin{array}{c}\text { Unknown; article not in } \\
\text { English }\end{array}$ & Good recovery \\
\hline 10 & $\begin{array}{l}\text { Piastra et al., } \\
2000^{12}\end{array}$ & $2 \mathrm{mos}$ & $M$ & $\begin{array}{c}\text { Not } \\
\text { reported }\end{array}$ & $\begin{array}{c}\text { Not } \\
\text { reported }\end{array}$ & Yes & Yes & $\begin{array}{l}\text { Surgical clipping \& } \\
\text { removal }\end{array}$ & Death \\
\hline 11 & $\begin{array}{l}\text { Sugino et al., } \\
2002^{13}\end{array}$ & 65 & $F$ & Yes & Mitral & Yes & Yes & $\begin{array}{l}\text { Unknown; article not in } \\
\text { English }\end{array}$ & Death \\
\hline
\end{tabular}

$\mathrm{SDH}=$ subdural hematoma.

In the clinical context, subdural empyema was presumed. The patient thus received surgery shortly thereafter for evacuation of the subdural empyema.

\section{Operative Report}

The patient was positioned for a standard frontotemporoparietal craniotomy for evacuation of the subdural empyema. After performing the craniotomy and durotomy, we immediately observed that the subdural collection contained both purulent and hemorrhagic components. Furthermore, active bleeding was noted from an arterial vessel. The artery was dilated and irregular, suggesting an MA. The vessel was resected, and the remainder of the subdural collection was evacuated. A subdural drain was placed, duraplasty was completed, and a bone flap was replaced. The incision was closed primarily. The resected vessel was sent for pathology, which confirmed the diagnosis of MA.

\section{Postoperative Course}

Postoperatively, the patient was monitored in the neurosurgical intensive care unit. Immediate postoperative CT imaging, including angiography, showed evacuation of the subdural collection and no evidence of aneurysm. The patient improved postoperatively and was neurologically intact with improved headache symptoms. On postoperative day 2, the patient had some intermittent expressive aphasia believed to be secondary to partial seizures. He was maintained on antiepileptic medication at a higher dose. The symptoms were transient and improved with no further issues during the hospital admission. The patient was ultimately discharged on postoperative day 6 to a rehabilitation facility with 6 weeks of antibiotic treatment and close follow-up.

\section{Discussion}

\section{Observations}

MAs are rare intracranial pathologies that typically present after rupture. The literature has indicated that MAs are clinically recognized in 3\%-10\% of patients with infective endocarditis and account for $<5 \%$ of all intracranial aneurysms. ${ }^{3}$ The presence of SAH or $\mathrm{ICH}$ has been reported to be the most common sequela of MAs rupture. The formation of a subdural hematoma as a consequence 

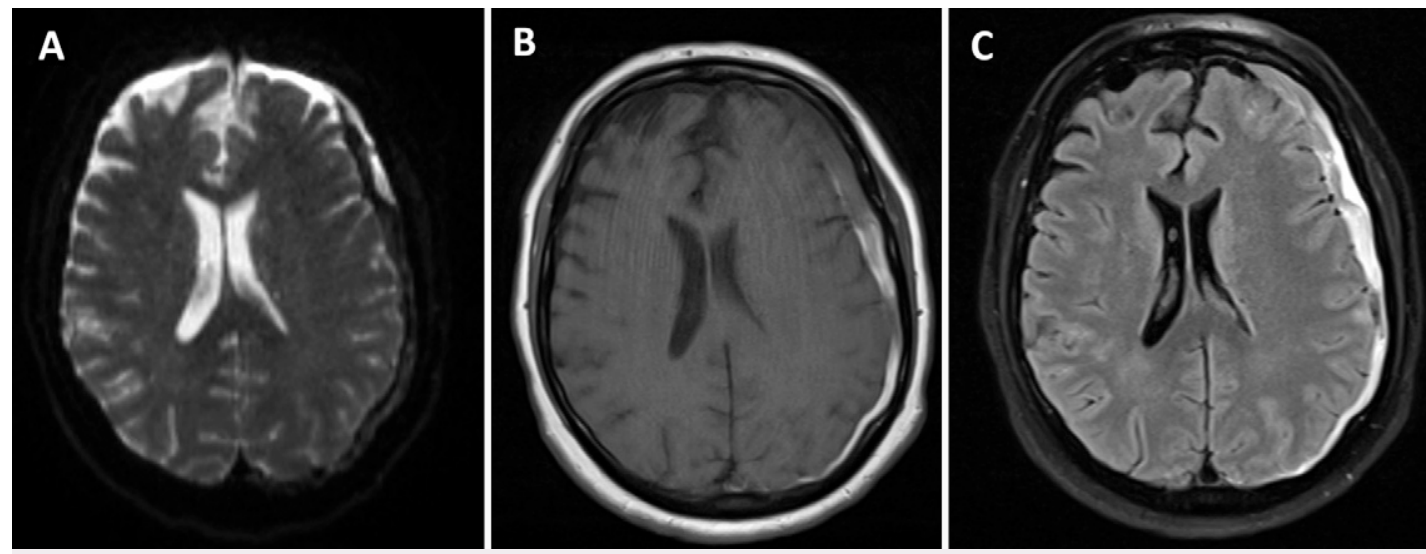

FIG. 1. MRI sequences showing subdural fluid collection. A: Diffusion-weighted imaging. B: T1-weighted imaging. C: Fluidattenuated inversion recovery imaging.

of MA rupture is far more atypical but has also been mentioned in the literature. We conducted a PubMed literature review to assess the frequency of subdural hematoma and subdural empyema formation as sequelae of MA rupture. In our literature review, we identified only 13 cases since 1960 of subdural hematoma formation in the setting of ruptured MAs and no reports of subdural empyema as a sequela of MA rupture (Table 1).

The mean age of the 13 patients in our literature review was 37.3 years (range: 2 months to 72 years). Six $(46 \%)$ of the patients were male and $7(54 \%)$ were female. Ten $(77 \%)$ of the 13 patients in our literature review presented with associated infective endocarditis, 1 patient did not, and information regarding this condition was missing for 2 patients. The most common cardiac valve involved in patients with infective endocarditis was the mitral valve (70\%), with the aortic valve being involved in 2 cases $(20 \%)$ and the mitral and aortic valves involved in 1 case $(10 \%)$. In addition to subdural hematoma in these patients, $3(23 \%)$ of them had additional associated $\mathrm{SAH}$, and $6(46 \%)$ of them had associated $\mathrm{ICH}$. In terms of outcomes, $6(46 \%)$ of the 13 patients recovered, whereas 1 patient $(8 \%)$ had mild memory disturbances and agraphia, 1 patient $(8 \%)$ was left in a vegetative state, and 3 patients $(23 \%)$ died. The outcomes of the remaining 2 patients in our literature review were not reported. The management strategy was reported for 9 patients. Of these patients, $5(56 \%)$ received craniotomy for removal of the aneurysm and blood, 2 (22\%) received endovascular glue embolization, and $2(22 \%)$ received antibiotic therapy without any surgical intervention.

Our case provides the first account of a patient with a subdural empyema in the setting of a ruptured mycotic cerebral aneurysm. Before the patient received surgery for evacuation, there was no clinical suspicion of mycotic cerebral aneurysm. During the operation, amid the mixture of purulent material and hematoma, the ruptured MA was identified and confirmed through pathology. When we retrospectively reviewed the patient's preoperative MRI, there was evidence of acute hematoma on the susceptibility-weighted sequence present within the subdural collection. Although this finding is most commonly associated with an acute or chronic subdural hematoma, in the setting of this patient's presentation with meningismus and positive blood culture results, an underlying MA as the cause of the subdural collection may have been considered.
However, the lack of more typical types of cerebral hemorrhages associated with MAs and lack of evidence on vascular imaging still makes that an unlikely connection, especially without any literature precedence. Fortunately, in this clinical situation, the MA was small and originated from a superficial cortical vessel that was managed intraoperatively without difficulty. However, a higher index of suspicion in cases with similar presentation and imaging findings is absolutely necessary to ensure that the appropriate team members and surgical equipment are available for management.

\section{Lessons}

Our patient presented with signs of meningeal irritation, infection, and infective endocarditis, all of which may have raised suspicion for an MA rupture. However, the presence of a subdural empyema without SAH or ICH placed this differential lower on the list of possibilities. Although this case report is limited by its nature of being a single case, it demonstrates an atypical presentation of MA rupture that has yet to be reported in the literature and thus contributes to an informed clinical judgment in the assessment of subdural empyema.

\section{References}

1. Suwanwela C, Suwanwela N, Charuchinda S, Hongsaprabhas C. Intracranial mycotic aneurysms of extravascular origin. J Neurosurg. 1972;36(5):552-559.

2. Boukobza M, Duval X, Laissy JP. Mycotic intracranial aneurysms rupture presenting as pure acute subdural hematoma in infectious endocarditis. Report of 2 cases and review of the literature. J Clin Neurosci. 2019;62:222-225.

3. Ducruet AF, Hickman ZL, Zacharia BE, et al. Intracranial infectious aneurysms: a comprehensive review. Neurosurg Rev. 2010;33(1): $37-46$.

4. Lee SM, Park HS, Choi JH, Huh JT. Ruptured mycotic aneurysm of the distal middle cerebral artery manifesting as subacute subdural hematoma. J Cerebrovasc Endovasc Neurosurg. 2013;15(3): 235-240.

5. Brust JCM, Dickinson PCT, Hughes JEO, Holtzman RNN. The diagnosis and treatment of cerebral mycotic aneurysms. Ann Neurol. 1990;27(3):238-246.

6. Bamford J, Hodges J, Warlow C. Late rupture of a mycotic aneurysm after "cure" of bacterial endocarditis. J Neurol. 1986;233(1): $51-53$. 
7. Bandoh K, Sugimura J, Hosaka Y, Takagi S. Ruptured intracranial mycotic aneurysm associated with acute subdural hematoma-case report. Neurol Med Chir (Tokyo). 1987 Jan;27(1):56-59.

8. Barami K, Ko K. Ruptured mycotic aneurysm presenting as an intraparenchymal hemorrhage and nonadjacent acute subdural hematoma: case report and review of the literature. Surg Neurol. .1994; 41(4):290-293.

9. Kasuya $H$, Shimizu T, Tajika $T$, et al. A case of septic aneurysm complicated with simultaneous subdural and intracerebral hematoma. Article in Japanese. No Shinkei Geka. 1985;13(10): 1109-1113.

10. King $A B$. Successful surgical treatment of an intracranial mycotic aneurysm complicated by a subdural hematoma. J Neurosurg. 1960;17(4):788-791.

11. Matsuda T, Kiyosue $H$, Yamashita M, et al. A case of multiple mycotic intracranial aneurysms presenting with subdural hematoma. Article in Japanese. No Shinkei Geka. 2002;30(1):73-78.

12. Piastra M, Chiaretti $A$, Tortorolo L. Ruptured intracranial mycotic aneurysm presenting as cerebral haemorrhage in an infant: case report and review of the literature. Childs Nerv Syst. 2000;16(3): 190-193.

13. Sugino T, Yamamoto K, Kidooka M, Otsuka S. A ruptured mycotic aneurysm, simultaneously associated with acute subdural hematoma and intracerebral hemorrhage: case report and review of the literature. Article in Japanese. No Shinkei Geka. 2002;30(11): 1211-1215.
14. Tsuboi M, Adachi H. A ruptured distal aneurysm, thought to be a mycotic aneurysm, associated with acute subdural hematoma: case report and review of the literature. Article in Japanese. No Shinkei Geka. 2002;30(2):177-181.

15. Yamakawa H, Hattori T, Tanigawara T, Enomoto $Y$, Ohkuma A. Ruptured infectious aneurysm of the distal middle cerebral artery manifesting as intracerebral hemorrhage and acute subdural hematoma: case report. Neurol Med Chir (Tokyo). 2003;43(11):541-545.

\section{Disclosures}

Dr. Yu reported personal fees from Synaptive Medical, Medtronic, and Haptic Systems outside the submitted work. No other disclosures were reported.

\section{Author Contributions}

Conception and design: Elhamdani, Jeong, Yu. Acquisition of data: Lucas, Elhamdani, Yu. Analysis and interpretation of data: all authors. Drafting the article: Lucas, Elhamdani, Jeong. Critically revising the article: Elhamdani, Jeong, Yu. Reviewed submitted version of manuscript: all authors. Approved the final version of the manuscript on behalf of all authors: Lucas. Statistical analysis: Lucas. Study supervision: Elhamdani, Jeong.

\section{Correspondence}

Joshua T. M. Lucas: Drexel University College of Medicine, Philadelphia, PA. jtmlucas8@gmail.com. 